\title{
The Evolution Of Casualty Evacuation In The British Army 20th Century (Part 1) -Boer War To 1918
}

\author{
MCM Bricknell
}

\begin{abstract}
This is the first in a series of papers which describe the evolution of the British casualty evacuation system in the 20th Century. This paper describes the formation of the Field Ambulance after the Boer War and the development of the Casualty Clearing Station during the First World War. It also discusses how the effects of an improved understanding of triage, shock and wound infection contributed to changes in the internal organization of hospitals in the field.
\end{abstract}

\section{Introduction}

'The importance of military medical history cannot be emphasized too strongly'(1).

This is the first in a series of papers which will review the evolution of the casualty evacuation chain during the 20th century. The first 3 will cover developments in the British Army. The fourth will examine some international experiences. The final paper will summarise the lessons and themes that might inform the development of operational military medical systems for the present and future.

The purpose of the review is to describe how developments in military technology, the experience of conflict, and improvements in the understanding of the pathophysiology of war wounds have led to changes in the organization of field medical services. The papers will describe how these changes have led to the creation of new or different medical units and also the effect of these changes on the internal organization of medical units, particularly hospitals. Military medical history provides us with many lessons and themes that remain as valid today as they did when first described. These will be highlighted in text boxes as signposts to the story.

The Journal of the Royal Army Medical Corps and the medical 'official histories' were the main sources used for these papers. This paper will describe the period from the Boer War to the end of the First World War.

\section{Boer War}

The British military medical services had been subject to considerable review during the 19th century, particularly following the failure of the medical system during the Crimean War. The Royal Army Medical Corps (RAMC) came into being in 1898 through the amalgamation of the Army Medical Staff and the Medical Staff Corps(2). The Boer War (Oct 1899 - May 1902) almost immediately put this new organisation to severe test. The war was characterised by British expeditionary columns seeking out Boer resistance groups who conducted 'guerrilla' style tactics. The army moved on foot with horse and ox driven transport. Most casualties were caused by small arms fire (rifles and machine guns) with little use of artillery against British forces. Anaesthesia was in widespread use in civilian surgical practice and the X-ray had recently been developed as a support to clinical diagnosis.

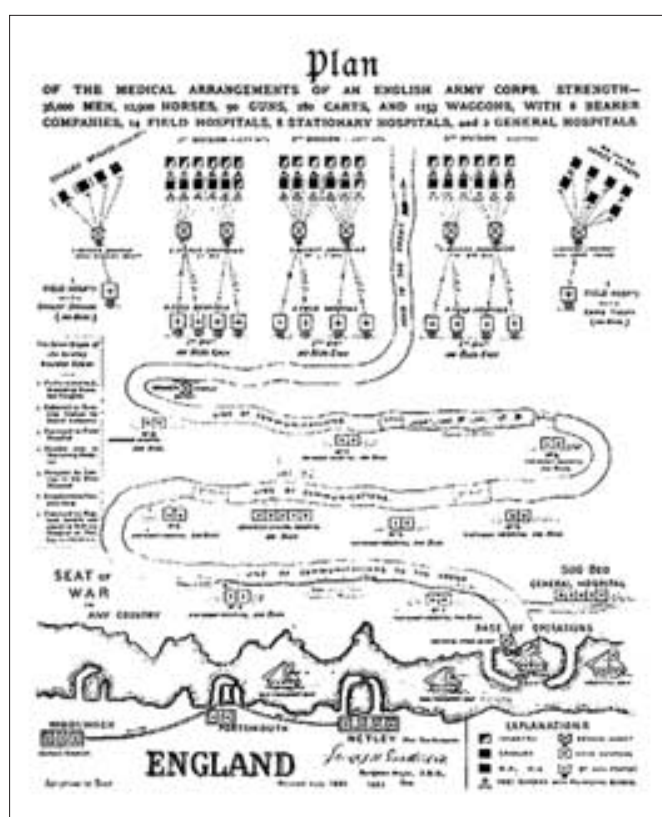

Fig 1. Chain of evacuation 1885.

The basic casualty evacuation chain was as described in the 'Field Service Manual' of 1899(3). This is summarised in Figure 1. At Regimental level there was a medical officer (appointed by the regiment) and 2 RAMC orderlies. In addition the regiment provided 16 stretcher bearers to assist in the recovery of casualties to the Regimental Aid Post. Casualty evacuation from the regiment was undertaken by the RAMC Bearer Company to the field hospital. There were four field hospitals allocated per division. The Hospital Train (a logistic unit of carts pulled by horses and oxen) was then responsible for the transfer of casualties from the field hospital to stationary hospitals and general hospitals.
Email:

mcm.bricknell@net.ntl.com 
A privately published pamphlet described the organization of field hospitals(4). 'Field hospitals are mobilised and managed, as regards the personnel, in a similar manner to bearer companies. As they are not supplied with beds, every effort should be made by means of straw etc to make them comfortable. The personnel of a bearer company encamped with a field hospital are available for assistance. The position of a field hospital is chosen near a water supply, and having regard to the facilities for evacuation by road, rail, water way, to the communication hospitals, as well as for evacuation to it from the bearer company in front.

\section{SITING OF MEDICAL UNITS: \\ water supply, evacuation routes to and from facility.}

After an action is over, all the medical units should be placed in advantageous positions, and the field hospital advanced to the wounded. A field hospital should be prepared to receive wounded by beginning with a few tents for the wounded, furnishing them with waterproof sheets, blankets etc and preparing operating tent, office and surgery, digging kitchens etc. One half of the hospital should be pitched first, the other half being kept in reserve to be utilised elsewhere if necessary'.

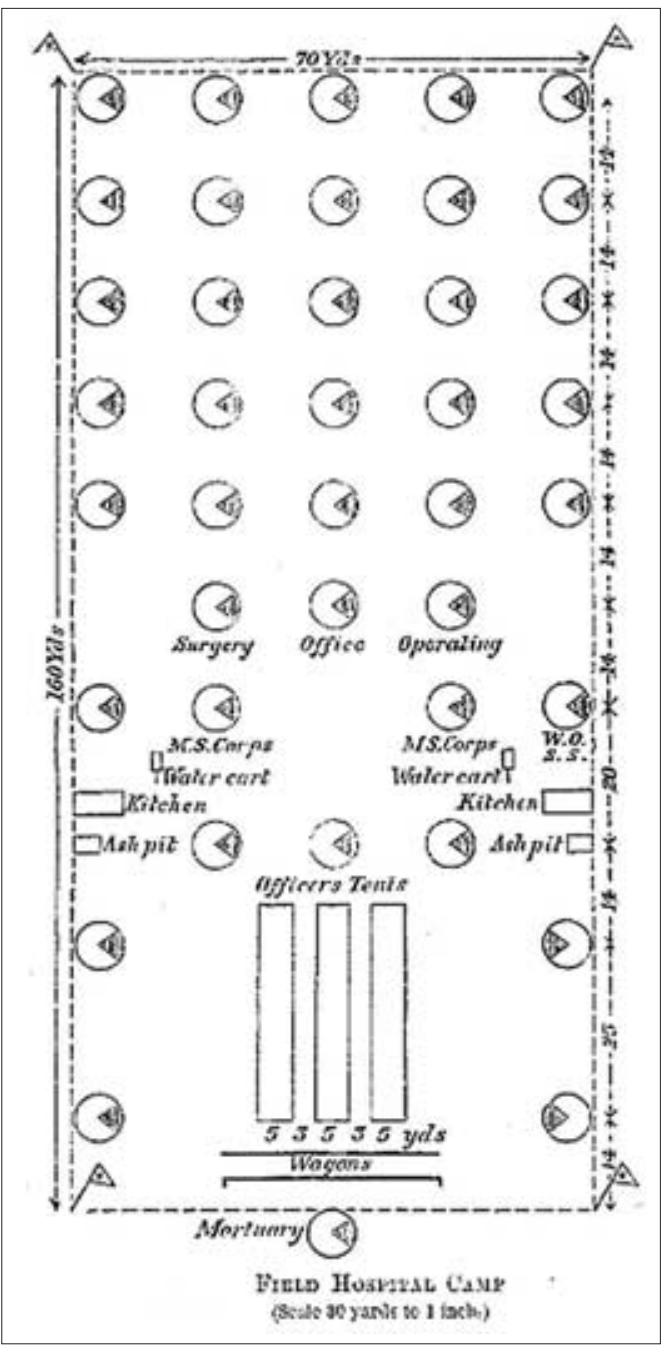

Fig. 2 Field Hospital Camp 1893.
A design of a field hospital camp was published in the Manual for the Medical Staff Corps 1893 and is shown in Figure 2 (5). The diagram shows little functional design to the internal layout of the unit implying that the unit was purely a collecting and holding area for casualties prior to onward evacuation. It should be noted that the field hospital was supplied with bell tents that were impractical for any prolonged treatment of patients.

Surgery at the field hospital was limited to amputations and wound dressing. Battle wounds were mainly caused by high velocity bullets. The bullet was about half the size it had been in previous wars and was reported not tend to carry in clothing. Contempory surgeons reported that these inflicted small wounds and tracks that seldom caused serious trouble (6). The dry, sandy 'velt' militated against the risk of wound infection compared to the highly agricultural land of the European theatre of the First World War. Thus neither debridement nor wound excision were practised. The work of the surgeon of a field hospital is richly described by Treves (7) at the battle of Collenso.

'It is needless to say that the operation-tent is very unlike an operating-theatre in a London Hospital, but the open veldt is very unlike the Metropolis. The floor of the tent is much trodden grass, and, indeed, much stained grass, for what drips upon it cannot be wiped up.... There is little room in the tent for others than the surgeon, his assistant, the anaesthetist, and a couple of orderlies. The surgeon is in his shirt-sleeves, and his dress is probably completed by riding breeches and a helmet. The trim nurses...whom form the gentlest element in the hospital theatre...are replaced by orderlies, men with burnt sienna complexions and unshaven chins, who are clad in the unpicturesque army shirt, in shorts, putties and the inevitable helmet or 'squasher' hat.....The wounded are brought into the marque one by one. Not all cases are for operation, but all have to be examined, and an examination is more easily carried out on a table than on a stretcher on the bare ground. Moreover to make the examination painless, an anaesthetic is usually required. I wonder how much choloroform and morphia were used on that day, and on the day and night that followed!'

\section{Lessons From The Boer War}

The Boer War exposed wide-ranging deficiencies in the Army's ability to conduct military operations. A committee under the chairmanship of Surgeon-General Wilson was appointed to report on the medical arrangements in the South African war and to make recommendations for improving the medical services for war (8).

\section{The Field Ambulance}

The main outcome of the war for medical services in the field was the amalgamation of the Bearer Company and Field Hospital into 
the Field Ambulance (8). It was found that work was unevenly distributed, the Bearer Company being frequently under employed whilst the Field Hospital was overworked (9). The new Field Ambulance was designed as a field medical unit capable of treating temporarily 100 to 150 sick or wounded. It was formed of a bearer division and a tent division. This unit would collect casualties from regiments and provide initial treatment at the Dressing Station (formed from one or more sections from the tent division). These were allocated to divisions on the basis of three field ambulances per division under divisional control (13). The Indian Field Hospital was seen to be a good example of this organisation as it comprised both a bearer company (including horse drawn ambulance wagons) and a tented division and it could easily divide into 4 sections combining both the means for transport and the means to treat the sick and wounded (10).

\section{The Clearing Hospital}

A division would also be supported by a field hospital (8). This unit was to be capable of providing some comfort to casualties by use of light stretcher beds and act as an evacuation hospital for the field ambulance units. The design of the 10th Canadian Field Hospital was recommended but the equipment scale increased to accommodate up to 200 patients (8). This design is shown in Figure 3.

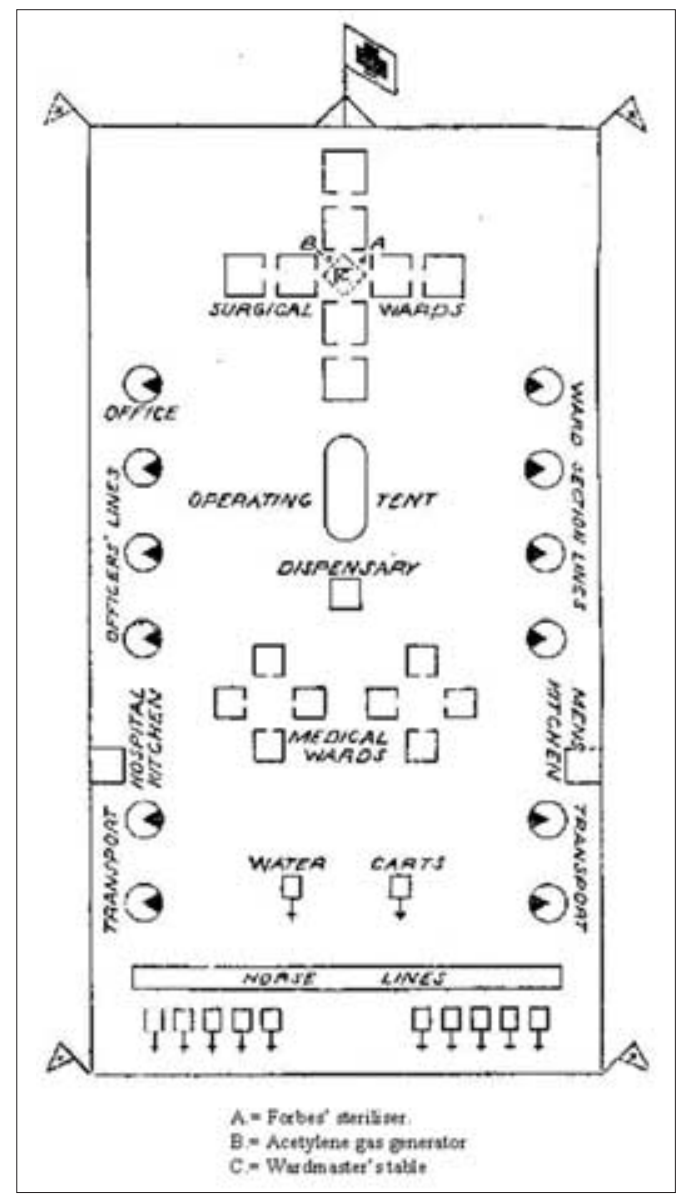

Fig 3. Plan of 10th Canadian Field Hospital.
The 'bell tents' of the field hospital (Figure 2) needed replacement with 'Hubert' pattern or tortoise tents. These were rectangular tents with a flysheet that were better suited to the environment and enabled a more orderly layout of patients internally. This design has a much clearer functional organisation compared to the previous field hospital. The unit was intended to be sufficiently mobile to march with the division to which it was attached. The Wilson report (8) recommended that it should be divisible into four sections of 50 beds, each section complete as regards tentage, stores, personnel, and transport.

MODULARITY: Field Ambulance sections of Tent Division to form Dressing Station, Clearing Hospital sections to form Hospitals.

The field ambulances with the brigades of the division would keep in constant touch by means of their ambulances with the larger and heavier field hospital following more slowly in the rear. They would constantly empty their sick and wounded into it, and the field hospital in its turn would evacuate by means of its ambulances into the nearest hospital on the lines of communication or nearest stationary hospital. Thus the field hospital would be specially organised for more permanent treatment of patients than had hitherto been the case, and its special function was to act as an evacuation hospital for the field ambulance units.

The divisional field hospital was established as the Clearing Hospital in 1905 as a result of the findings of the Escher Commission. The Clearing Hospital was the pivot upon which the whole system of evacuating sick and wounded depended (11). Thus the adjective 'Clearing' developed a specific military medical meaning.

FUNCTIONS OF A CLEARING
HOSPITAL
a.to receive and treat until fit for further
transport the seriously ill sick and wounded
soldier
b. to expedite the immediate evacuation of
those fit to travel to the base area
c. to retain for early return to duty, those cases
of wounds and sickness likely to recover
within a few days.

The first was a hospital function, the second an evacuation function and the third function was to reduce loss of manpower from fighting formations. It should be within a day's march of the field, about 8-10 miles from the front line. The term 'clearing' emphasises its role to remain empty for as long as it could by handing patients over to a stationary unit or passing them down the line of communication. Although it was a mobile unit it had no transport of its own; this was to be provided by the Inspector General of 
Communications. It also had to be able to send on detachments to provide rest stations for the line of evacuation should distances between units become extended(12).

\section{Chain Of Evacuation}

The changes in field medical units described above significantly altered the design of the chain of evacuation compared to that used in the Boer War. MacPherson (13) describes three zones for the organisation of services for the removal of the sick and wounded from the battlefield: the collecting zone, the evacuating zone and the distributing zone. The collecting zone contains the unit medical organisations and the field ambulances. The evacuating zone contains the clearing hospitals, ambulance trains and advanced depots of medical stores. Finally the distributing zone contains the stationary and general hospitals. This is shown graphically in Figure 4 (14).

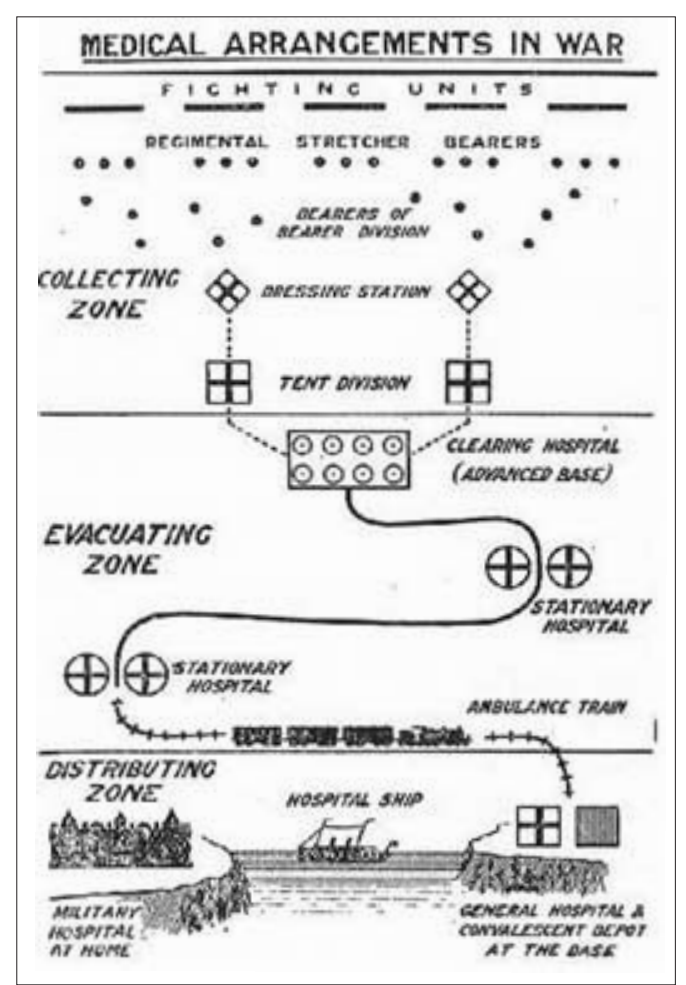

Fig 4. The Chain of Evacuation 1906-1914.

The formation of the Field Ambulance and the Clearing Hospital created a single 'pipeline' for the evacuation of casualties from the front line. The plan for movement of casualties from the Clearing Hospital to Stationary Hospital was based on the use of empty wagons under the control of the Director of Transport. This created a potential conflict between the needs of the medical system and the needs of the supply system and was the main limitation of this new system.

TRANSPORT: outside medical control for the movement of casualties and Clearing Hospitals.

\section{World War 1}

The European front in World War 1 was dominated by the machine gun and field artillery. This gave superiority to the defence and created the 'stalemate' whereby both sides were forced into direct assaults with the consequent cost in lives. The internal combustion engine was in widespread use for motor transport, this led to replacement of animal drawn carriages in many areas of the Army. Gas was first used as a weapon though the consequences of this upon the medical services will not be considered in this paper.

\section{The Opening Phases}

The British Army medical services started World War 1 organised as described in the previous section. The medical services had not had the opportunity to become fully established before the opening battles of the war. Initially the large number of casualties overwhelmed the small staffs of the Clearing Hospitals $(\mathrm{CH})$. The treatment of casualties was limited solely to the dressing of wounds and evacuation further down the line of communication. At the First Battle of Ypres some 13,000 wounded men were moved down the evacuation chain, many wounded only receiving surgery for their injuries after arrival in England(15). Motor ambulances were first employed to move wounded to the railhead on 20th September 1914. This led to the formation of the Motor Ambulance Convoy for the movement of casualties from the Dressing Station of the Field Ambulance rearwards.

\section{TRANSPORT: although the MAC was a logistic unit it came under control of the medical services for the movement of casualties.}

The Western Front stabilised in November 1914 resulting in the $\mathrm{CHs}$ becoming more static. This led to the employment of female nursing sisters within the $\mathrm{CH}$ and the provision of beds. During 1915 the Clearing Hospital was renamed as the Casualty Clearing Station (CCS) and its equipment was increased, substantially adding to its surgical potential. Thus wounded could be operated on and retained within the CCS until fit to move. The treatment of a casualty was now based on clinical grounds and not solely on the need to 'clear' the division of casualties.

EVACUATION: retention of casualties at CCS until fit for evacuation.

\section{Evolution OfThe Casualty Evacuation Chain}

The general scheme for the evacuation of casualties evolved during the 4 years of war. The final scheme was published in the Journal of the Royal Army Medical Corps in 
1926 (16). This is summarised in Figure 5. The Field Ambulance and the CCS had been confirmed and the Motor Ambulance Convoy (MAC) established since the experience from the Boer War. A new collection point, the Walking Wounded Collection Point (WWCP), had been developed to relieve the divisional evacuation chain from the burden of moving these casualties who could evacuate themselves.

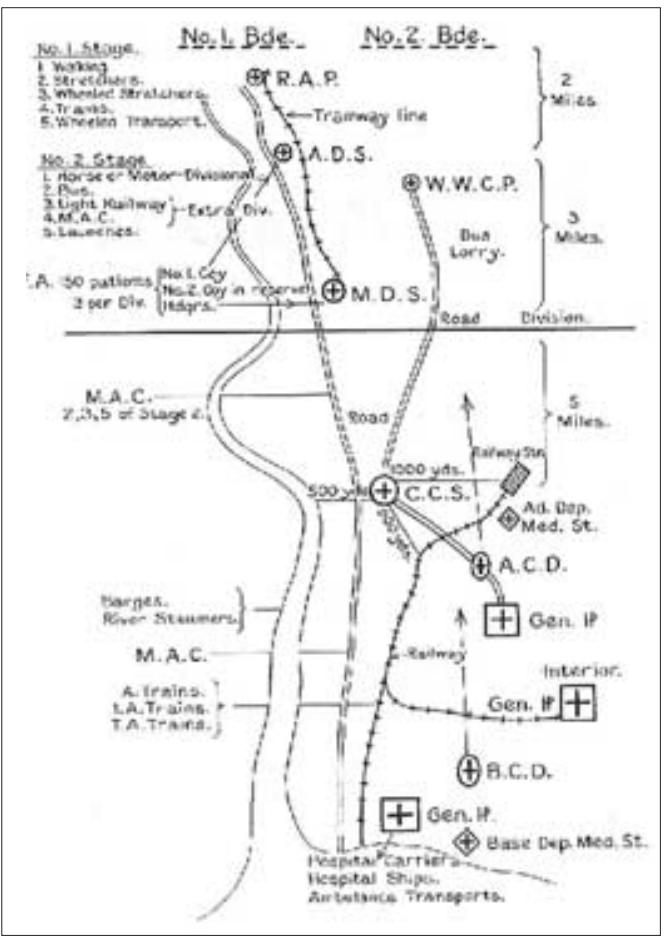

Fig.5. Casualty evacuation $W W$.

The Motor Ambulance Convoys were responsible for all movement of casualties by vehicle, both from the Dressing Stations to the CCSs and from the CCSs to the railhead. The original system of collecting large numbers of casualties in dressing stations and moving them en masse by convoy to CCSs was replaced by the movement of urgent cases as rapidly as possible. Ambulance trains were used to move casualties from the CCS to General Hospitals in large hospital areas. The casualty was evacuated to the UK if he was unlikely to return to fighting fitness or needed a long period of convalescence.

\section{TRIAGE: clinical prioritisation for evacuation}

\section{The Development Of The \\ Casualty Clearing Station}

By early 1915 large numbers of operations were being undertaken within the CCSs and the most severely injured casualties were being retained until fit to be moved. During the latter half of the year, it was agreed between the medical services and the Royal Engineers that CCSs would be equipped with two huts, each 60 feet long, one for the operating theatre and one for dressings (17). The operating hut was to be divided into 3 rooms, one for giving the anaesthetic, one for surgery and one for sterilising. Two new departments were added, a resuscitation ward for the treatment of shock, and a preoperation ward for the removal of clothing from patients before transfer to the operating theatre.

CCSs were established in open ground with good road communication from the front and a dedicated railway siding for the onward evacuation of casualties. An experiment was also undertaken to examine the possible role of 'advanced operating centres' based on dressing stations closer to the front. However it was found that better results were obtained by operating on casualties in the CCS where casualties could be held and treated in beds post-operatively rather than moved soon after operation.

The battle of the Somme led to the further expansion of CCSs and their siting in groups. This allowed the flow of casualties to be diverted between CCSs on the basis of time or number of casualties to allow the staff to complete the treatment of casualties after admission and arrange for their evacuation before receiving the next group. This method was further refined by the specialisation of CCSs so that those receiving the more seriously injured could be spared the turbulence caused by the walking wounded strolling about to seek out friends and creating considerable amounts of noise in talking to them. Thus CCSs were becoming differentiated into the individual roles of the Clearing Hospital described earlier rather than retaining the capability to deliver all 3 functions.

TRIAGE: clinical prioritisation by destination (CCS), casualty regulation. SURGERY: best performed in CCS unless evacuation was delayed.

In September 1916 the DGMS directed the examination of arrangements to provide the CCSs with greater mobility in order to enable them to provide clinical care whilst being redeployed. This split the CCS into a light section, able to move on 3 nine ton lorries, and a heavy section that would move after the casualties had been cleared from the facility. The proportion of tents to huts was increased. In order to increase mobility further, two specially modified aeroplane trailers were supplied to each army to move the clinical equipment for the operating theatre. The trailer superstructure was designed to be lifted off the trailer by 4 men. Inside there were cupboards and shelves to store all of the equipment needed for the operating theatre (18).

MOBILITY: modularisation of CCS, bespoke shelter systems. 


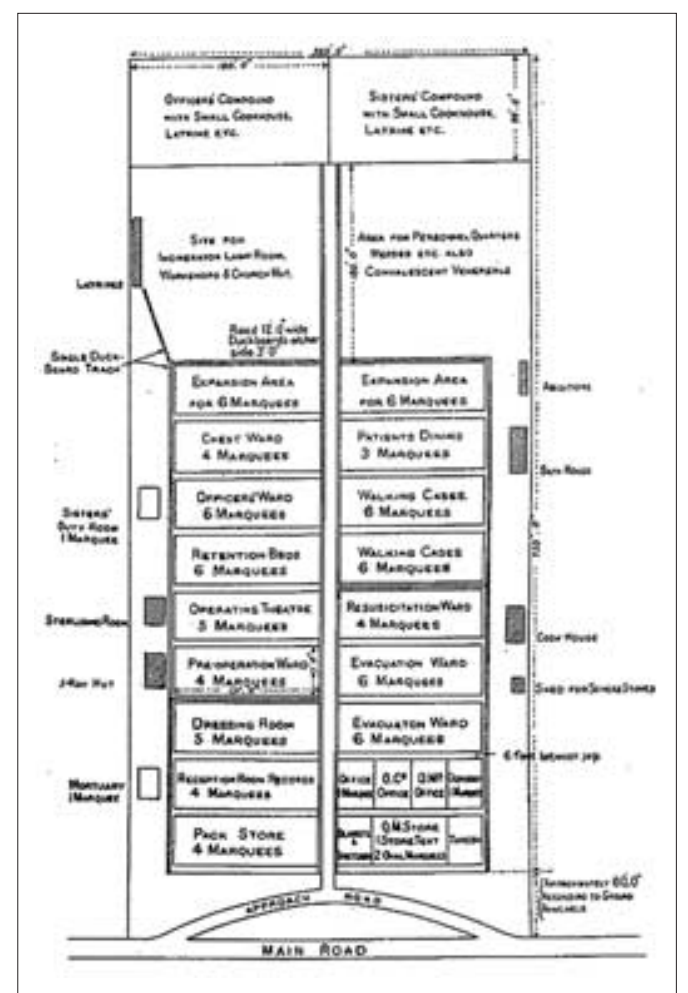

Fig 6. Plan of Fifth Army Casualty Clearing Station in 1917 to accommodate 600 patients.

The division of the CCS persisted after the war such that the light section was equipped for 50 serious and 150 light cases and the heavy section 150 and 250 cases respectively. The light section being able to move forward to take over wounded from a Main Dressing Station and establish an 'Advanced Operating Centre' (16).

In September 1917 the equipment holding for CCSs had been standardised to provide for admission of 200 seriously wounded and up to 800 less seriously wounded whilst they awaited evacuation. By 1918 the whole CCS was housed in a series of lashed tents. A general scheme for the arrangement of CCSs had become established. A general plan is shown at Fig 6 (19).

This was a considerable evolution in functional design compared to the Canadian field hospital (Figure 3). A paper published in 1919 described the detailed working of a CCS (20). Separate receiving rooms were established for lying cases and walking cases. Walking cases who had slight wounds were passed through the dressing tent for evacuation without the need to be taken through the complex. The lying case receiving room was kept as empty as possible to ensure that all casualties could be accommodated. The officer in the receiving room rapidly assessed each case in turn, marking their destination within the unit. If an operation was required, the casualty's clothes were removed and replaced with pyjamas in the pre-operation tent. If he was suffering from shock or exposure he was placed in the resuscitation tent prior to operation. Designs were developed for operating theatres based on linking several tents together. The operating tables being arranged in pairs so that the surgical team could move from one patient to the next whilst other staff moved patients on and off the tables. This arrangement is shown in Figure 7. After operation the patient could be either put in a bed and retained or returned to a stretcher for evacuation dependant on his clinical condition.

TRIAGE: clinical prioritisation in order for treatment

As more surgery was being undertaken within CCSs, X-ray units became an integral part of the organisation. Initially these were of variable quality but as time went on it was recognised that each CCS should be

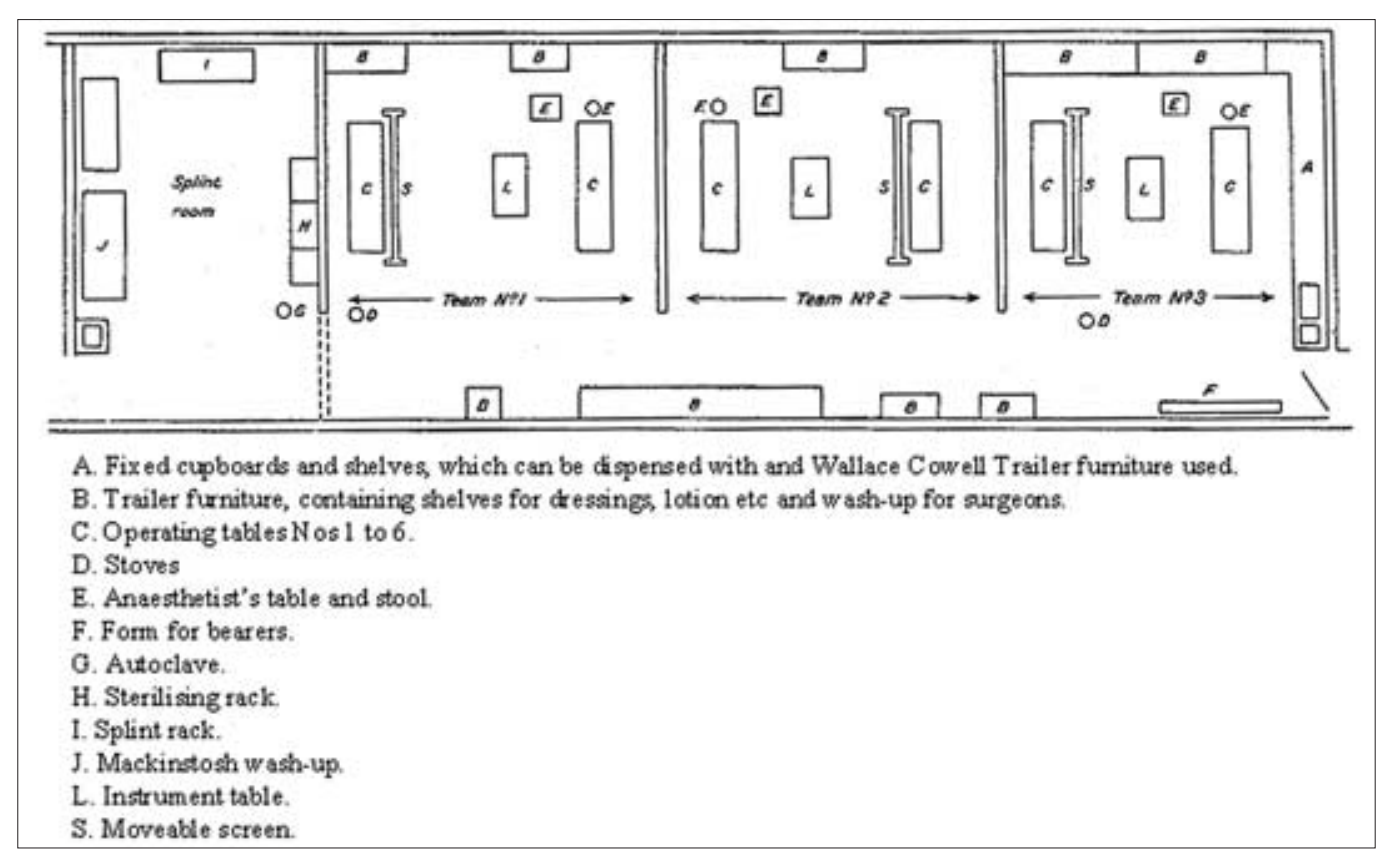

Fig 7. The layout of an operating theatre in a CCS. 
provided with a lorry which carried all the Xray equipment and provided the power supply. Pathological laboratories mounted in specially designed lorries were also attached to groups of CCSs so as to support clinical practice and also to conduct research into shock and gas gangrene(21).

The manpower of the CCS expanded in parallel with the expansion in equipment. The role of female nursing sisters was firmly established. A system of reinforcements by 'surgical teams' was a further refinement in the flexibility in the system to provide surgical support to CCSs during major battles. These could be moved between CCSs or drawn forward from base hospitals. During 1917 developments in surgical technique led to the formal 'excision' and 'irrigation' of war wounds as a method to reduce the risk of wound infection.

\section{SURGERY: creation of mobile surgical teams to reinforce CCSs. SURGERY: wound excision}

Nurses were trained in the administration of anaesthetics in order to free up medical officers for other duties and to cope with the consequent increase in the number of operations required on the wounded. Resuscitation became a formal clinical treatment for surgical shock involving warming of casualties, rectal infusions with saline and transfusion of blood. The transient effects of saline for the maintenance of blood pressure in shock were appreciated. Gum saline (6 per cent gum acacia and 0.9 percent saline) was introduced to alleviate this. Initially blood transfusion was direct from donor to patient, clotting being prevented by treatment of the connecting cannulae and tubing with paraffin. The use of citrated blood was introduced in 1917. This enabled donors to be bled in advance in anticipation of casualties. These developments led to the creation of resuscitation teams and departments in 1917 and 1918 (22).

The medical services of both of the Canadian and Australian armies had come into existence as a result of each country's experience of the Boer War. Both modelled their medical organisation and units on the British system and thus utilised field ambulances, motor ambulance convoys and casualty clearing stations (still called Clearing Hospitals by the Australians) in the forward zone $(23,24)$.

\section{Summary}

The organisation of medical services for war was transformed by the experience of the Boer War and refined during the First World War. The field medical system had developed a treatment function within the CCS alongside the evacuation function of the Field Ambulance and the Motor Ambulance Convoy. This military context was dominated by the static conditions and high casualty rates of the Western Front leading to large fixed facilities based on CCSs sited at the limit of the range of the enemy's artillery. Casualty evacuation behind the DS was now undertaken using specially designed motor ambulances. The immobility of the CCS remained as the main constraint of the field medical system.

Developments in clinical practice drove the evolution of the internal organisation of the CCS. The problem of wound infection led to the concept of early surgery for the excision of dead tissue and removal of foreign debris, thus substantially increasing the surgical workload within the forward area. The problem of the 'immovable' abdominal case led to the surgery and retention of these cases in the CCS and transformed the prognosis of these wounds from certain death to possible survival. Improvements in the understanding of shock led to the development of the concept of resuscitation and the embryonic formation of a blood supply and transfusion service. X-ray and laboratory support was pushed forward to the CCS to provide additional diagnostic support.

The next paper in this series will describe the development in casualty evacuation in the British Army up to the end of the Second World War. The paper will show how some of the same lessons identified during the First World War were re-learned and how others were developed as a result of advances in military and medical technology.

\section{Acknowledgement}

This project was supported by a short-term research fellowship in the history of medicine from the Wellcome Trust.

\section{References}

1. Cantlie N. Forward. History of the Second World War. United Kingdom Medical Series. The Army Medical Services. Administration. Volume 1. Ed FAE Crew. HMSO London 1953.

2. Summers A. Medical men and military matters: the BMJ and the Victorian army. Bd Med f 1990; 301: 717-20.

3. Gubbins WL. Field Medical Organisation - The lessons of the War. I Roy Army Med Corps 1904; 2:446-451

4. WIHM RAMC 2049 3/3 Notes on Medical services in WarWH McNamara Brigade Surgeon Lieutenant Colonel Gale and Polden Aldershot 1895.

5. Manual for the Medical Staff Corps. War Office 1893.

6. Fettes D. Fifty years of surgery in the Royal Army Medical Corps. F R Army Med Corps 1948; 90:271281.

7. Treves F. The tale of a field hospital. Cassell and Company. London 1900.

8. Wilson WD. Report on the Medical Arrangements in the South African War. HMSO London 1904.

9. Editorial. The Field Ambulance. $\mathcal{F}$ R Army Med Corps 1906; 6:690-2.

10. Jones TP. A report upon the transport of the sick and wounded in the field. F R Army Med Corps 1904; 3: 584-592.

11. Russell MW. The role of the Clearing Hospital. $\mathcal{F}$ Roy Army Med Corps 1910; 14: 603-10.

12. Royal Army Medical Corps Training. War Office London 1911. 
13. MacPherson WG. The removal of the sick and wounded from the battlefield. I Roy Army Med Corps 1909;12:78-88.

14. Tufnell AW. Lines of Communication with special reference to the medical services. I $\mathrm{R}$ Army Med Corps 1910;15:202-219.

15. History of the Great War. Medical Services. Surgery of the War. Volume 1. Eds MacPherson, Bowlby, Wallace and English. HMSO London 1922.

16. Mitchell TJ. Some guiding principles in the evacuation of casualties. F R Army Med Corps 1926; 21-36.

17. MacPhail A. Official History of the Canadian Forces in the Great War 1914-9. The Medical Services. FA Acland Ottawa. 1925.

18. Cowell EM. The Wallace-Cowell Theatre Trailer. $\mathcal{F} R$ Army Med Corps 1917;28:708-722.

19. MacPherson WG. History of the Great War. Medical Services. General History. Volume II. The medical services on the Western Front, and during the operations in France and Belgium in 1914 and 1915. Eds MacPherson, Bowlby, Wallace and English HMSO London 1923.

20. Goodwin WRP. The Casualty Clearing Station as a working Unit the field. F R Army Med Corps 1919; 23:42-57.

21. History of the Great War. Medical Services. Medical Services Pathology. Eds MacPherson, Bowlby, Wallace and English. HMSO London 1923.

22. Resuscitation Manual. Equipment, organization and procedures. London HMSO.

23. Snell AE. The CAMC. With the Canadian Corps during the last hundred days of the Great War. FA Acland Ottawa 1924.

24. Butler AG. The Australian Army Medical Services in the War of 1914-8. Volume II. Australian War Memorial Canberra 1940 